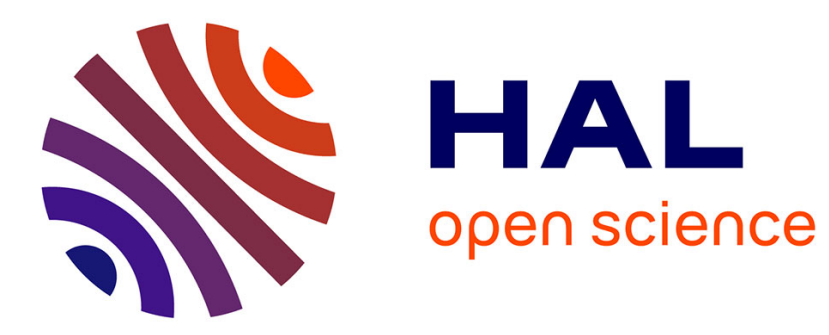

\title{
Devices based on Light Emitting Fabrics dedicated to PDTpreclinical studies
}

E Thecua, L Ziane, G Baert, P. Deleporte, B. Leroux, A. Kumar, M Baydoun, O Morales, N Delhem, Serge Mordon

\section{- To cite this version:}

E Thecua, L Ziane, G Baert, P. Deleporte, B. Leroux, et al.. Devices based on Light Emitting Fabrics dedicated to PDTpreclinical studies. "The Feminine" 51st IPA Congress, Jul 2019, Londres, United Kingdom. hal-02518762

\section{HAL Id: hal-02518762 \\ https://hal.science/hal-02518762}

Submitted on 25 Mar 2020

HAL is a multi-disciplinary open access archive for the deposit and dissemination of scientific research documents, whether they are published or not. The documents may come from teaching and research institutions in France or abroad, or from public or private research centers.
L'archive ouverte pluridisciplinaire HAL, est destinée au dépôt et à la diffusion de documents scientifiques de niveau recherche, publiés ou non, émanant des établissements d'enseignement et de recherche français ou étrangers, des laboratoires publics ou privés. 


\title{
Devices based on Light Emitting Fabrics dedicated to PDTpreclinical studies
}

\author{
E. THECUA ${ }^{1}$, L. ZIANE ${ }^{1} *$, G. BAERT ${ }^{1}$, P. DELEPORTE ${ }^{1}$, B. LEROUX ${ }^{1}$, A. KUMAR ${ }^{2}$, M.

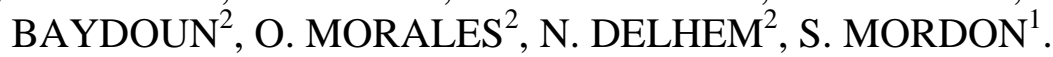 \\ ${ }^{1}$ Univ. Lille, Inserm, CHU Lille, U1189 - ONCO-THAI - Image Assisted Laser Therapy for \\ Oncology, Lille, France \\ ${ }^{2}$ UMR 8161, CNRS, Institut de biologie de Lille, Institut Pasteur de Lille, Université Lille-Nord de \\ France, 59000 Lille, France
}

* These authors contributed equally to this work

\begin{abstract}
Whether preclinical studies either involve a cell or animalmodel, the distribution of light plays a determinant role in the reproducibility of results of photodynamic therapy (PDT) studies. Unfortunately, only few illumination devices dedicated to preclinical studies are available and are for the most, very expensive. Mostresearch teams use home-made solutions that may not always be reproducible because of undefined light distribution, additive thermal emission, or unsuitable for shapes and volumes to illuminate.
\end{abstract}

To address these issues, we developed illumination devices dedicated to our preclinical studies, which embed knitted light emitting fabrics (LEF) technology. LEF technology offers a homogeneous light distribution, without thermal emission and can be coupled with various light sources allowinginvestigation of several PDT modalities (irradiance, wavelength, illumination duration/mode).

For in-vitro studies, we designed light plates,each allowing illumination of up to four 96-cells plates. For in-vivo studies, we designed mice boxes allowing three animals placement in prone position, equally surrounded by LEF and ensuring homogeneous extracorporeal illumination.

Optical validation was performed and reproducibility of both preclinical systems were assessed.

Both systems can deliver homogeneous light with an irradiance that can reachseveral $\mathrm{mW} / \mathrm{cm}^{2}$, with varying durations and wavelengths. First results of preclinical studies demonstrate a high reproducibility, with an easy setup, and a great adaptability of illumination modalities with these devices based on light emitting fabrics.

Keywords:Light emitting fabrics, textile, optical, fibers, bending, PDT, preclinical studies, illumination, MDB TEXINOV

\section{INTRODUCTION}

Over the last decades, photodynamic therapy (PDT) has proven to be efficient for certain types of cancer [1, 2]. Widely used in dermatological practice, PDT is one of the first-line treatments for the management of actinic keratosis and superficial basal cell carcinomas [3]. Furthermore, several preclinical and clinical trials suggest that PDT in intraoperative conditions represents a promising complementary therapeutic modality for the management of invasive cancers in neurosurgery, pneumology, otolaryngology and gynecology [4-7]. Indeed, in spite of shallow light penetration into biological tissues, photodynamic therapy is particularly appropriate for the treatment of subclinical lesions scattered in the cavity after maximal surgical removal of the tumor [8].

Therapeutic effect of PDT depends on a combination of parameters that include photosensitizer (PS)concentration, druglight interval, oxygen in cells, fractionation mode, wavelength and total dose of light distributed in biological tissues [9]. To date, PDT parameters are under many investigations, as many for increasing direct tumor cell death rates as for 
understanding immune-modulation aspects [10]. Whatever the fields of research (Chemistry, Physics, Biology, etc.), investigation teams have to choose a light source suitable to preclinical studiesthey undergo.To our knowledge, only few illumination devices dedicated to in vitro or in vivo PDT studies are available and they are for the most, very expensive. As a result, most research teams use home-made solutions or adapt optical fiber devices primarily dedicated to the human clinic [11-13].

In vivo preclinical studies laser sources are widely used as they provide high intensity with narrow spectral distribution. LASER sources can easily be associated to frontal end optical fibers or cylindrical diffuser end optical fibers previously introduced into tumor sites to perform intralesional illumination[13-15]. As visible light depth penetration within biological tissues is limited to few millimeters [16], external illumination are mostly dedicated to superficial lesions or in vitro studies. External illuminations can be performed in intracavitary locations with optical fiber devices (panels, balloons or cylindrical diffuser) $[12,17-21]$ and in topical locations with frontal end optical fibers, LASER beams or LED panels [22-26].

Whether preclinical studies either involve a cell or animal model, lightplays a determinant role in the reproducibility of results. An undefined spatial and/or spectral light distribution or unsuitable for shapes and volumes to illuminate, andadditive thermal emissions during illumination, could result in inconsistent dosing [26] and slow down preclinical studies and thusthe development of a modality that can be clinically useful and benefit patients. To address these issues, we developed illumination devices dedicated to our preclinical studies, which embed knitted light emitting fabrics (LEF) technology.

\section{MATERIALS AND METHODS}

\subsection{Light emitting fabrics with knitting warp technology}

Developed in the framework of CIP PHOS-ISTOS European project, light emitting fabrics (LEF) technology consists in the integration of step index optical fibers (TORAY, Tokyo, JAPAN) with a polymethyl methacrylate (PMMA) core and a fluorinated claddingwithin a fabric structure during the knitting process. Controlling macrobendings and yarn tension during the knitting process, homogeneous light emission over the entire surface of the sample can be obtained.Produced in one step by warp knitting technology, LEF are made of polyester yarn and embed $37 \mathrm{POF} / \mathrm{cm}^{2}$ and can have an effective area over $500 \mathrm{~cm}^{2}$ while keeping flexible and conformable properties. [27, 28]

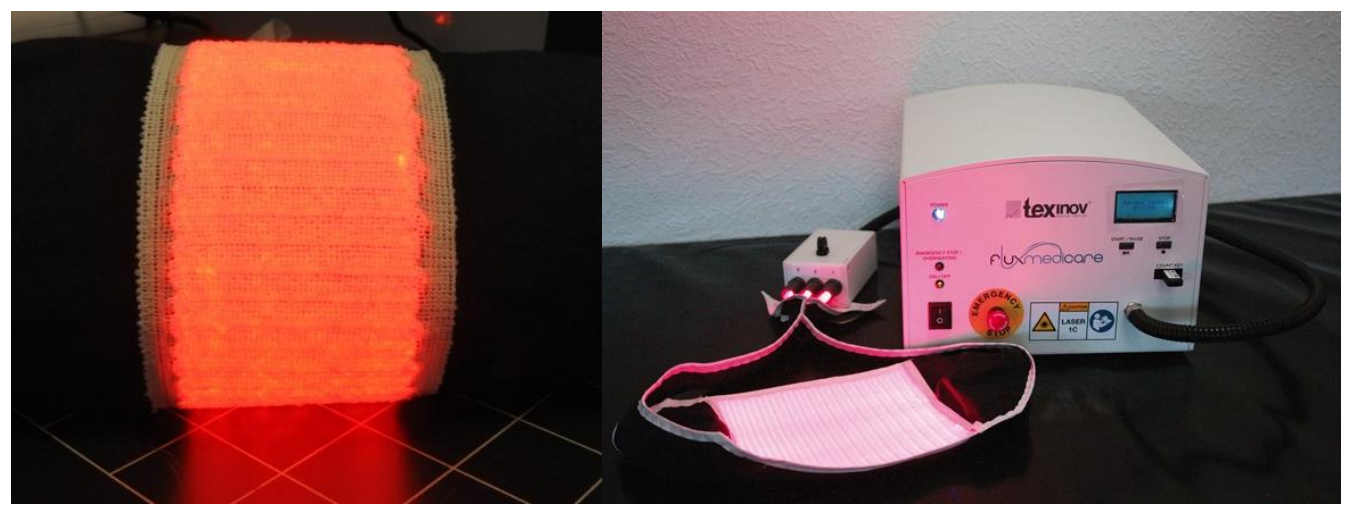

Figure 1. Light emitting fabric sample coupled to $635 \mathrm{~nm}$ LASER source (left) and FLUXMEDICARE® device (right)

Several clinical studies using LEF for PDT of actinic keratosis have been published [29, 30] and launched industrialization of FLUXMEDICARE device (MDB TEXINOV, Saint Didier de La Tour, FRANCE). LEF technology appeared also as a relevant and reliable lighting solution for PDT preclinical studies as no additive thermal emission have been described [27, 31].

Gathering free plastic optical fibers within a metallic bundle allow LEF to be coupled to anyLASER source by the mean of 2 beam expanders. Thereby, LEF results on a passive light emitting surface, such as frontal or cylindrical diffuser end optical fibers. 


\subsection{In vitro preclinical devices based on light emitting fabrics}

In-vitro PDT preclinical studies often mobilize several operating conditions that should be conducted simultaneously or within a short period of time.

To our in-vitro PDT preclinical studies, two light plates have been designed. Each light plate embeds $600 \mathrm{~cm}^{2}$ of LEF allowing the simultaneous illumination of up to four 96-cells plates.Transparent plasticsheets provide hygienic barrier and water protectionto light emitting fabrics, and can be cleaned and disinfectedbefore/after each use.Lightproof black covers allow the operator to stay in the room by preventing additional activation of the PS with stray light and preventinternal light reflection that can lead to inconsistent dosing.

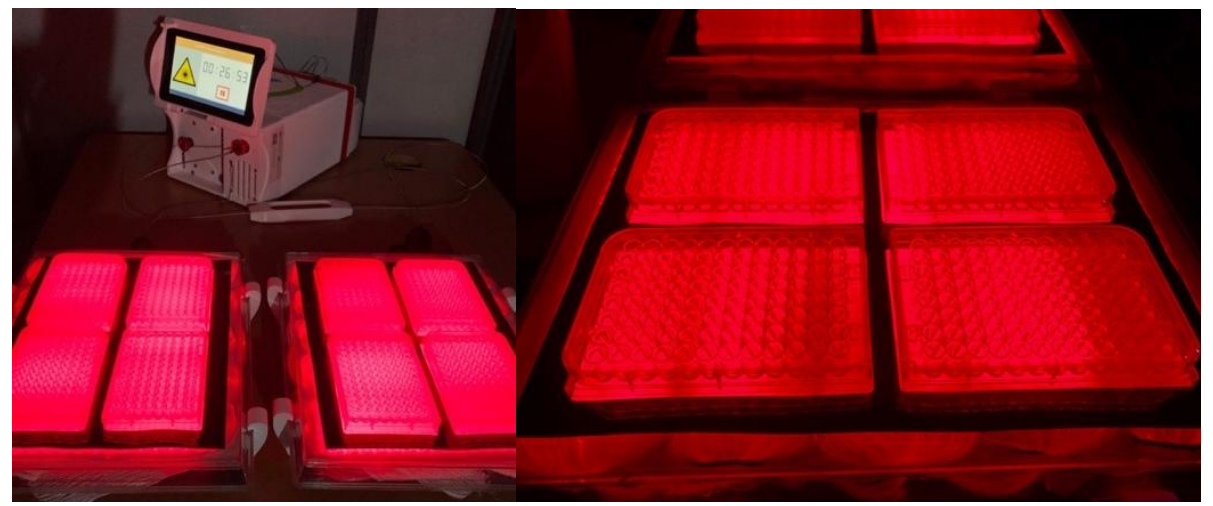

Figure 2. Light plates connected to $670 \mathrm{~nm}$ LASER source without black covers

\subsection{In vivopreclinical devices based on light emitting fabrics}

In the framework of the development of an original humanized SCID mouse model of ovarian peritoneal carcinomatosis, a specific device dedicated to mice illumination has been designed. Inspired from results published on mice extracorporeal PDT $[11,32]$ we designed a mice box allowing three animals placement in prone position, equally distributed on $250 \mathrm{~cm}^{2}$ of LEF. Equally surrounded by LEF, full body illumination is provided, with the exception of the headto allow continuous gas anesthesia.Disposable plastic protections provide a hygienic barrier and isolate animals from the LEF.

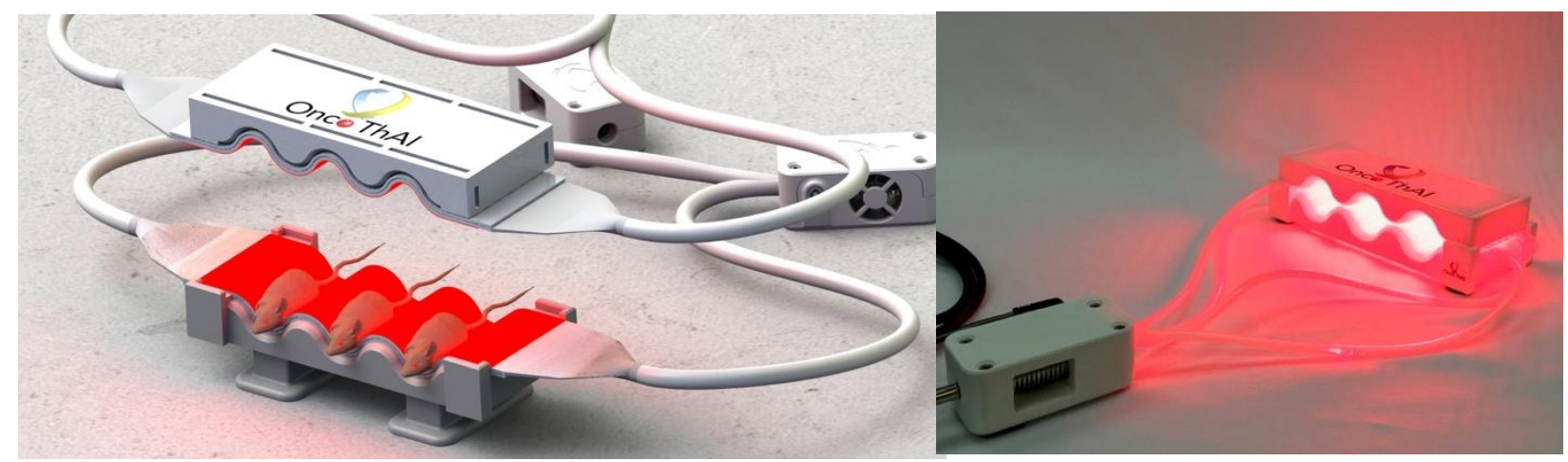

Figure 3. Micebox connected to $670 \mathrm{~nm}$ LASER source - picture with mice (Left), photo withoutmice (Right)

\subsection{Measurements methodology}

Positioning templates were used to hold an opto-electronic sensor (PD300, OPHIR, Israel) and a power meter (Laserstar, OPHIR, Israel) in 12 holes regularly placed over all effectiveareas. The measurement process required maintaining each devicein a blind room, while connected to a $670 \mathrm{~nm}$ LASER source (OncoThAI, Lille,FRANCE)of a total output power settled on $8.5 \mathrm{~W}$ for the mice box, and $7.1 \mathrm{~W}$ for light plates. Mean irradiance is calculated for each target area: Three cavities forthe mice box, andfourcells plates areas of each light plate. 
International standard IEC 60601-2-57 defines safety and performances of devices designed to create photobiological effects on humans or animals, for therapeutic, diagnostic applications in the wavelength range of $200 \mathrm{~nm}$ to 3000 nm.International standard IEC 62471, specifies corresponding exposure limits to evaluate the photobiological safety of light source for operators.According to both standardswe conducted measurements of the accessibleemission from light plates and mice boxes where connected to $635 \mathrm{~nm}$ or $670 \mathrm{~nm}$ LASER sources at a standardized distance of $10 \mathrm{~cm}$ with a photodiode sensor (PD300RM, OPHIR, Israel) and a power meter (Laserstar, OPHIR, Israel).The accessible emission informs us on the safety risk category according to which light sources must be classified and handled with personal protective equipmentand special care.

\section{RESULTS AND DISCUSSION}

To date, preclinical devices have been used around eighty times for the light plates, and ten times for the mice box.[33]

First results of preclinical studies demonstrate a high reproducibility, with an easy setup, and a great adaptability of illumination modalities with these devices based on light emitting fabrics.

As the mice box and light plates can be light in by connecting an opticalfiber patch to any LASER source of whatever wavelength, several PDT light modalities (irradiance, fractionation, light dose) have been undergone very easily.

\subsection{Irradiance}

Each target area of light plates andmice box delivered respectively $1.26 \pm 0.27 \mathrm{~mW} / \mathrm{cm}^{2}$ and $11.08 \pm 0.58 \mathrm{~mW} / \mathrm{cm}^{2}$, witha global effective optical yield of $22 \%$ resp. $33 \%$.

Considering effective surface of all optical fibers, corresponding to optical fiber core only, theoretical yields of the bundle connectors are $70 \%$. Relatively low yield of light plates can be easily explained by the delicate task that represents gathering and mixing several thousand plastic optical fibers within a metallic bundle.Laser gaussian beam distribution remains a critical point in LEF connection: by keeping only the central part of the laser beam reach the bundle full of fibresprovides homogeneous light distribution but induces significant losses.

Fluence rate delivered within biological materials (cell lines, and peritoneal cavity of nude mice) are currently under investigation.

\subsection{Photobiological Evaluation}

According to both IEC 60601-2-57 and IEC 62471 standard methodologies, all PDT preclinical devices fulfill light exposure limits, and can be used safely without personal protective equipment.Retinal blue light hazard, retinal thermal hazard and thermal hazard exposure limits of "Risk Free Group" where above accessible emission of our devices.

\section{CONCLUSION}

To overcome the lack of affordable light sources suitable to PDT preclinical studies, we developed illumination our own devices dedicated to our in-vitro and in-vivo preclinical studies, which embed knitted light emitting fabrics (LEF) technology. For in-vitro studies, we designed light plates,each allowing illumination of up to four 96-cells plates. For invivo studies, we designed mice boxes allowing three animals placement in prone position, equally surrounded by LEF and ensuring homogeneous extracorporeal illumination. Optical validation was performed and both preclinical systems can deliver reasonably homogeneous light with an irradiance that can reachseveral $\mathrm{mW} / \mathrm{cm}^{2,}$ with varying durations and wavelengths.

\section{REFERENCES}

[1] U. Chilakamarthi, and L. Giribabu, "Photodynamic Therapy: Past, Present and Future," Chem Rec, 17(8), 775802 (2017).

[2] P. Agostinis, K. Berg, K. A. Cengel et al., "Photodynamic therapy of cancer: an update," CA Cancer J Clin, 61(4), 250-81 (2011). 

photodynamic therapy," Eur J Dermatol, 25(4), 296-311 (2015).

[4] M. Ascencio, P. Collinet, M. Cosson et al., "[The place of photodynamic therapy in gynecology]," Gynecol Obstet Fertil, 35(11), 1155-65 (2007).

[5] R. Diez Valle, C. G. Hadjipanayis, and W. Stummer, "Established and emerging uses of 5-ALA in the brain: an overview," J Neurooncol, 141(3), 487-494 (2019).

[6] C. Munck, S. R. Mordon, A. Scherpereel et al., "Intrapleural Photodynamic Therapy for Mesothelioma: What Place and Which Future?,” Ann Thorac Surg, 99(6), 2237-45 (2015).

[7] R. R. Allison, R. E. Cuenca, G. H. Downie et al., "Clinical photodynamic therapy of head and neck cancers-A review of applications and outcomes," Photodiagnosis Photodyn Ther, 2(3), 205-22 (2005).

[8] H. W. Wang, T. C. Zhu, M. E. Putt et al., "Broadband reflectance measurements of light penetration, blood oxygenation, hemoglobin concentration, and drug concentration in human intraperitoneal tissues before and after photodynamic therapy," J Biomed Opt, 10(1), 14004 (2005).

[9] B. W. Henderson, and T. J. Dougherty, "HOW DOES PHOTODYNAMIC THERAPY WORK?," 55(1), 145 157 (1992).

[10] J. M. Dabrowski, and L. G. Arnaut, "Photodynamic therapy (PDT) of cancer: from local to systemic treatment," Photochem Photobiol Sci, 14(10), 1765-80 (2015).

[11] M. C. Geralde, I. S. Leite, N. M. Inada et al., "Pneumonia treatment by photodynamic therapy with extracorporeal illumination - an experimental model," Physiol Rep, 5(5), (2017).

[12] L. Guyon, J. C. Lesage, N. Betrouni et al., "Development of a new illumination procedure for photodynamic therapy of the abdominal cavity," J Biomed Opt, 17(3), 038001 (2012).

[13] G. Shafirstein, D. Bellnier, E. Oakley et al., "Interstitial Photodynamic Therapy-A Focused Review," Cancers (Basel), 9(2), (2017).

[14] D. S. Pellosi, L. B. Paula, M. T. de Melo et al., "Targeted and Synergic Glioblastoma Treatment: Multifunctional Nanoparticles Delivering Verteporfin as Adjuvant Therapy for Temozolomide Chemotherapy," Molecular Pharmaceutics, 16(3), 1009-1024 (2019).

[15] M. Vermandel, M. Quidet, A.-S. Vignion-Dewalle et al., "Comparison of different treatment schemes in 5-ALA interstitial photodynamic therapy for high-grade glioma in a preclinical model: An MRI study," Photodiagnosis and Photodynamic Therapy, 25, 166-176 (2019).

[16] B. C. Wilson, and M. S. Patterson, "The physics, biophysics and technology of photodynamic therapy," Phys Med Biol, 53(9), R61-109 (2008).

[17] C. E. Grossman, S. L. Carter, J. Czupryna et al., "Fluence Rate Differences in Photodynamic Therapy Efficacy and Activation of Epidermal Growth Factor Receptor after Treatment of the Tumor-Involved Murine Thoracic Cavity,” Int J Mol Sci, 17(1), (2016).

[18] C. E. Grossman, S. Pickup, A. Durham et al., "Photodynamic therapy of disseminated non-small cell lung carcinoma in a murine model," Lasers in surgery and medicine, 43(7), 663-675 (2011).

[19] C. E. Grossman, S. L. Carter, J. Czupryna et al., "Fluence Rate Differences in Photodynamic Therapy Efficacy and Activation of Epidermal Growth Factor Receptor after Treatment of the Tumor-Involved Murine Thoracic Cavity," International journal of molecular sciences, 17(1), 101 (2016).

[20] C. Grossman, T. Zhu, J. Finlay et al., "Targeted laryngeal photodynamic therapy with a balloon diffusing light source," Photodiagnosis and photodynamic therapy, 7(3), 158-161 (2010).

[21] E. Oakley, D. A. Bellnier, A. Hutson et al., "Surface markers for guiding cylindrical diffuser fiber insertion in interstitial photodynamic therapy of head and neck cancer," Lasers Surg Med, 49(6), 599-608 (2017). 
[22] M. Fadel, N. Samy, M. Nasr et al., "Topical colloidal indocyanine green-mediated photodynamic therapy for treatment of basal cell carcinoma," Pharm Dev Technol, 22(4), 545-550 (2017).

[23] T. Gracia-Cazaña, M. Mascaraque, S. R. Lucena et al., "Biomarkers of basal cell carcinoma resistance to methyl-aminolevulinate photodynamic therapy," PloS one, 14(4), e0215537-e0215537 (2019).

[24] M. S. Mathews, E. Angell-Petersen, R. Sanchez et al., "The effects of ultra low fluence rate single and repetitive photodynamic therapy on glioma spheroids," Lasers Surg Med, 41(8), 578-84 (2009).

[25] S. R. Lucena, A. Zamarrón, E. Carrasco et al., "Characterisation of resistance mechanisms developed by basal cell carcinoma cells in response to repeated cycles of Photodynamic Therapy," Scientific reports, 9(1), 48354835 (2019).

[26] E. Austin, and J. Jagdeo, “An In Vitro Approach to Photodynamic Therapy,” Journal of visualized experiments : JoVE(138), 58190 (2018).

[27] C. V. E. Thecua, A-S. Vignion, F. Lecomte, P. Deleporte, et al., "Light emitting fabric for photodynamic treatment of actinic keratosis."

[28] J. B. Tylcz, C. Vicentini, and S. Mordon, [4 - Light emitting textiles for a photodynamic therapy] Woodhead Publishing, Oxford(2016).

[29] C. Vicentini, A. S. Vignion-Dewalle, E. Thecua et al., "Photodynamic therapy for actinic keratosis of the forehead and scalp: a randomized, controlled, phase II clinical study evaluating the non-inferiority of a new protocol involving irradiation with a light-emitting, fabric-based device (the Flexitheralight protocol) compared with the conventional protocol involving irradiation with the Aktilite CL 128 lamp," Br J Dermatol, (2018).

[30] S. Mordon, A. S. Vignion-Dewalle, H. Abi-Rached et al., "The conventional protocol versus a protocol including illumination with a fabric-based biophotonic device (the Phosistos protocol) in photodynamic therapy for actinic keratosis: a randomized, controlled, non-inferiority clinical study,” Br J Dermatol, (2019).

[31] S. Mordon, C. Cochrane, J. B. Tylcz et al., "Light emitting fabric technologies for photodynamic therapy," Photodiagnosis Photodyn Ther, 12(1), 1-8 (2015).

[32] H. W. Guo, L. T. Lin, P. H. Chen et al., "Low-fluence rate, long duration photodynamic therapy in glioma mouse model using organic light emitting diode (OLED)," Photodiagnosis Photodyn Ther, 12(3), 504-10 (2015).

[33] M. Baydoun, O. Moralès, C. Frochot et al., "Intraperitoneal Photodynamic Therapy for Ovarian Cancer: A Novel Way to Stimulate Anti-tumoral Immune Response?." 